\title{
A Theoretical Review of the Speech Act of Suggesting: Towards a Taxonomy for its Use in FLT ${ }^{1}$
}

\author{
Alicia Martínez-Flor \\ Jaume I University \\ aflor@ang.uji.es
}

\begin{abstract}
The aim of this paper is to present a taxonomy of linguistic realisation strategies concerning the speech act of suggesting. In this regard, we will first provide a definition of this particular speech act, outlining its main characteristics and differentiating it from other directive speech acts, such as requests. Second, we will review the research conducted on suggestions by examining studies from both the cross-cultural and interlanguage pragmatics fields. Third, we will present the taxonomy we have drawn up on the basis of two theoretical frameworks, namely those of speech act and politeness theories, as well as findings from previous studies on this particular speech act. Finally, we will propose an example of a teaching approach in which this taxonomy could be implemented in order to develop learners' pragmatic competence when making suggestions.
\end{abstract}

\section{Introduction}

This paper constitutes an attempt to present a taxonomy of different linguistic realisation strategies for the speech act of suggesting. Employing such a taxonomy in foreign language teaching (FLT) could provide learners with a range of particular forms for use as suggestions in different situations. With a view to implementing this taxonomy in the foreign language classroom, the present paper aims to expand the pragmatic features examined in the field of interlanguage pragmatics (ILP), such as requests, compliments, 
apologies, refusals or complaints, by describing a speech act that has not been widely examined - that of suggestions; and proposing activities for its use in FLT.

\section{The speech act of suggesting}

\subsection{Definition and characteristics}

Suggestions belong to the group of directive speech acts which, according to Searle (1976), are those in which the speaker's purpose is to get the hearer to commit him/herself to some future course of action. Put more simply, directives are attempts to make the world match the words. Bach and Harnish's (1979) definition of directives also implies that the speaker's attitude and intention when performing an utterance must be taken as a reason for the hearer's action. Moreover, one relevant feature affecting directives in opposition to other speech acts, such as representatives or commissives (Searle 1976), refers to the necessary interaction between the speaker and the hearer in order to get the speech act performed. As Trosborg (1995: 20) points out, "only in the case of directives is the hearer's subsequent act (getting things done) part of the speaker's intention". For this reason, as argued by Alcón and Safont (2001), when dealing with directive speech acts, both the interlocutors' presence and their response to speakers' intentions are fully required, since the action will only be fulfilled after the hearer's acceptance of the speaker's intentions. As stated by Thomas (1995), both speaker and hearer are to be taken into account when producing directive speech acts.

Focusing specifically on the different speech acts included within the group of directives, Schmidt and Richards (1980) claim that it contains speech acts such as requests, commands and suggestions, the main goal of which is to get the hearer to do something, although the force of the attempt can differ from one speech act to another. Taking into account the assumption that there are different kinds of directives, Haverkate (1984) provides a specific definition for exhortative speech acts which also implies that the speaker wants the hearer to do something. This author distinguishes between impositive and nonimpositive directives. The former group includes more threatening acts, such as requesting, pleading and ordering, whereas non-impositive directives refer to suggestions and instructions. The main difference between these two groups lies in the fact that the benefits obtained by carrying out an impositive speech act are exclusively for the speaker, whereas the objective of the non-impositive speech acts is to benefit the hearer. Thus, a clear distinction between requests and suggestions is important, since both speech acts belong to the same category of directives and, as suggested by Thomas (1995), one relevant principle of pragmatics involves the fact that some speech acts may overlap. For this reason, previous literature addressing directives has already distinguished requests and suggestions on the basis of the benefit of the action (Searle 1969; Rintell 1979; Edmonson and House 1981; Banerjee and Carrell 1988; Trosborg 1995). As Rintell (1979: 99) states, "in a suggestion, the speaker asks the hearer to take some action which the speaker believes 
will benefit the hearer, even one that the speaker should desire".

However, although suggestions are made in the best interest of the hearer, according to Brown and Levinson's (1987) politeness theory, this speech act is regarded as a facethreatening act (FTA) since the speaker is in some way intruding into the hearer's world by performing an act that concerns what the latter should do. In this sense, suggestions are regarded as an imposition upon the hearer by affronting his/her negative face (Banerjee and Carrell 1988). As these authors claim, if a speaker decides to make a suggestion, several factors should be considered, such as the urgency of the suggestion, the degree of embarrassment in the situation, and the social distance and power between the speaker and the hearer (Brown and Levinson 1987). For this reason, and depending on these factors and the extent to which the situation can be more or less threatening, the speaker might try to soften or mitigate this speech act through the use of specific politeness strategies in order to minimise, as far as possible, the chances of the hearer's being offended.

After defining suggestions, as a directive and an FTA, and having distinguished them from requests, it is also worth mentioning that suggestions may be regarded as components of a broader speech act that involves the act of advice. This assumption is made on the grounds that inclusive-we suggestions can imply benefits for both the speaker and the hearer, whereas a piece of advice is in the sole interest of the hearer (Edmonson and House 1981; Trosborg 1995). However, in this paper, we will only deal with non-inclusive suggestions (Koester 2002: 169), since we are adopting the perspective that the hearer's action will only benefit him/herself. As will be reviewed in the next subsection, which deals with all studies that pay attention to this speech act, research shows that traditionally the terms "suggestions" and "advice acts" have been employed interchangeably to refer to the same speech act (Searle 1969; Wardhaugh 1985; Wierzbicka 1987; Banerjee and Carrell 1988; Bardovi-Harlig and Hartford 1993, 1996; Tsui 1994; Koike 1996; Hinkel 1997; Mandala 1999; Matsumura 2001, 2003). In order to exemplify this assumption, we have chosen two studies from the ones mentioned above. On the one hand, the study conducted by Banerjee and Carrell (1988) focused on the speech act of suggesting. However, in order to provide a definition of this speech act, the authors (1988: 318) state that suggestions have been termed by Searle as advisement, since Searle (1969: 66-67) makes a distinction between requests and advice. On the other hand, Mandala (1999) focused on the speech act of advice, but quoted two different studies that have dealt with suggestions in order to explain her concepts of advice recipients (Bardovi-Harlig and Hartford 1993) and advice-givers (Banerjee and Carrell 1998). Moreover, Tsui (1994) has also described advisives as a type of directive speech act that advocates a course of action for the benefit of the hearer, arguing that although the acts of advising, suggesting and recommending may have been treated as three separate acts in the speech act literature, they are in fact, different labels for the same type of advisive speech act.

Bearing in mind all these characteristics that define the speech act of suggestions, we will now go on to examine the research that has addressed this speech act, whether it be regarded as a suggestion or advice, in order to provide the basis on which our proposed taxonomy is founded. 


\subsection{Research on suggestions}

With regard to research dealing with the speech act of suggesting, Schmidt et al. (1996) claim that suggestions have received less attention in comparison to the speech act of requesting, which has been extensively investigated. In their own words, the authors (1996: 287-288) state that "in analysing commercials as suggestions, we are somewhat hampered by the lack of detailed studies of this speech act [...] requests have been investigated extensively, but the speech act of suggestion, a cousin of the request, has been much less studied". Moreover, most of the research that has dealt with this speech act, as well as the studies that have regarded suggestions as advice acts, consists of cross-cultural pragmatic studies (Rintell 1979; Boatman 1987; Banerjee and Carrell 1988; Altman 1990; Hu and Grove 1991; Wierzbicka 1991; Hinkel 1994, 1997), with only a few studies from the field of ILP (Bardovi-Harlig and Hartford 1990, 1993; Koike 1994, 1996; Alcón 2001; Matsumura 2001, 2003). A detailed description of these studies is provided in the two subsections that follow.

\subsubsection{Cross-cultural pragmatics studies on suggestions}

The first study based on suggestions was conducted by Rintell (1979). Rintell (1979) focused on Spanish students' communicative competence when employing requests and suggestions in both their native language and English as a Second Language (ESL). The author chose these two directive speech acts in order to examine deference when the variables of age and sex of the addressee were manipulated in the role-plays. Results showed that suggestions were less deferential than requests and that the factors of age and sex affected deference in suggestions only in English. As regards age, Rintell found that it was significant in both languages, although sex was significant only in Spanish. The author concluded that no transfer occurred in the Spanish participants' use of pragmatic rules when employing the two speech acts under examination. Apart from this study, Banerjee and Carrell (1988) were the first scholars to conduct research specifically designed to focus on suggestions. By employing a discourse completion test (DCT) consisting of 60 situations that elicited a suggestion, these authors compared two groups of subjects, namely those of Chinese and Malay ESL students with 12 native speakers (NSs) of American English. Results from the study were analysed both quantitatively, as far as frequency, directness and type of suggestion employed, and qualitatively, regarding the use of politeness strategies and redressive forms when suggesting. The authors found that NSs made suggestions more frequently than non-native speakers (NNSs), and the type of suggestion used depended on the directness of the situation. Particularly interesting in this early study is the fact that these authors addressed the issue of instruction by posing the question "What should we be teaching in ESL classrooms that will help students when making suggestions?" (1988: 317). Likewise, they proposed several pedagogical implications by suggesting different steps that could be adopted to teach this particular speech act. 
Other important cross-cultural pragmatics studies were those conducted by Hinkel $(1994,1997)$. Although the author mentioned that she focused on advice, she talked about "forms of suggestions or advice" indistinctively (1994: 77). These studies are particularly relevant, since some of the linguistic forms addressed by this author have been adopted in our proposed taxonomy. Hinkel's (1994) study focused on the differences between how 31 NSs of American English and 203 NNSs judged the appropriateness of advice in different situations. In order to establish these differences, the author employed written role-plays in the format of a multiple-choice test (MCT) consisting of 16 situations that involved two characters, namely those of a social superior, that is a college teacher with a higher status, and a peer acquaintance with the same status as the students who were involved in the research. Regarding her classification of the speech act of advising, the author relied on the theoretical frameworks established by Li and Thompson (1981), Wardhaugh (1985), Brown and Levinson (1987), Lii-Shih (1994) and Wierzbicka (1991), and classified advice acts into either direct, hedged or indirect advice acts. Results indicated that both NSs and NNSs were aware of the social distance involved between them and their interlocutors. Moreover, Hinkel reported that the NSs made a noticeable distinction between the superior and the peer by employing indirect comments with the instructor and she also found that, in addition, NSs' advice was predominantly hedged with both interlocutors. In another study, Hinkel (1997) focused on the differences between speakers of Chinese and NSs of English when dealing with the appropriateness of advice acts, on the one hand, and the differences between employing two research instruments, namely those of DCTs and MCTs, on the other hand. The Chinese subjects' responses tended to include indirect advice acts when responding to the DCT situations, whereas more direct strategies were preferred for the MCT. According to Hinkel (1997), responses to the MCT indicated what the author had previously hypothesised, since advice acts in Chinese are regarded as acts of solidarity.

\subsubsection{Interlanguage pragmatics studies on suggestions}

The study conducted by Bardovi-Harlig and Hartford in 1990 was the first one to address suggestions from a developmental perspective. This ILP study was also the first of a series of studies by the same authors to be placed in the academic setting of an advising session $(1990,1993,1996)$. The authors were interested in examining authentic conversations between advisors and students in order to pay attention to the status congruence between both parties, that is to say, whether the linguistic forms employed by the two interlocutors were congruent with their respective status. They defined congruence as "the match of a speaker's status and the appropriateness of speech acts given that status" (1990: 473). This study addressed the speech act of suggesting as a non-congruent speech act for students according to their status and, at the same time, it showed the importance of using statuspreserving strategies, especially downgraders (House and Kasper 1981), to minimise the threat of learners' suggestions. By comparing the linguistic negotiation of status between NSs and NNSs, the authors concluded that they differed in their pragmatic competence, 
since NNSs, although highly competent linguistically, did not have the ability to employ the status-preserving strategies in accordance with their status.

On the basis of the previous study, Bardovi-Harlig and Hartford (1993) carried out a longitudinal study which examined suggestions and rejections within the same framework of status congruence. The participants consisted of 16 graduate students (6 NSs and 10 NNSs of English) and 7 native English-speaking faculty members. Both groups of subjects were taped in 35 advising sessions over the course of a semester in order to examine the change over time in the students' ability to develop their pragmatic competence. Results from this study showed that NNSs' pragmatic competence improved over time, as was shown by their making better suggestions and achieving a better status balance. However, students did not show a better ability to employ appropriate forms of the speech act of suggesting, which according to the authors could be due to a lack of appropriate input regarding suggestion formulae. Although Bardovi-Harlig and Hartford $(1990,1993)$ did not provide a specific typology regarding the linguistic forms of suggestions, their studies are particularly important, since these authors identified certain congruent speech acts in a specific setting (that of the advising session) and attributed different speech acts for the advisor and the student. Thus, advisors are assumed to perform the acts of advising, recommending and requesting information, whereas speech acts congruent with student status are those of requesting advice, information and permission.

Taking these two studies into consideration, Alcón (2001) developed a cross-sectional investigation that also examined the speech act of suggesting within the framework of status congruence in an ESL setting. In her study, the author taped 30 sessions involving 15 Spanish students and analysed the suggestions taking into account both frequency and form. Results from this study indicated that, although NNSs received positive input by teachers, students' percentage of direct forms and the absence of mitigators showed their lack of pragmatic competence. In this sense, Alcón (2001) suggests that being exposed to the language is not enough to develop learners' pragmatic competence and, thus, she points out that pedagogical intervention is necessary in the context of academic advising sessions.

Koike $(1994,1996)$ also conducted some studies focusing on whether negation can be regarded as a mitigation device when performing suggestions and on the effects of proficiency in a study of pragmatic transfer. Koike's (1994) analysis about negation in suggestions and requests compared the Spanish and English languages. Results from her study indicated that the use of the negative in English suggestions made them more forceful than in Spanish, since in English the negative is optional. However, the author concluded that neither in suggestions nor in requests was negation used to soften or mitigate the utterance. For the purposes of the present paper, this research is important because Koike proposed commonly used suggestion forms in English (1994: 521), some of which have been adopted in our taxonomy of suggestions presented in the following subsection. In another study, Koike (1996) developed a cross-sectional study focusing on the awareness of suggestions by 114 English learners of Spanish at different levels of proficiency and on pragmatic transfer from their mother tongue to the foreign language. The data was obtained from responses to a questionnaire that students had to complete after watching a videotape 
with seven speech acts. Results showed that proficiency was important, since advanced students understood the true intent of the speech acts, whereas the other students failed to comprehend it. There were no proficiency effects at play in pragmatic transfer, since transfer occurred at different levels of proficiency. Koike (1996) concluded that learners of a foreign language need to be exposed to contextualised language in order to recognise speech acts at both grammatical and pragmatic levels of use.

Finally, the studies conducted by Matsumura $(2001,2003)$ on the speech act of advice are also situated within the field of ILP. Following Hinkel's (1997) study, Matsumura (2001) carried out a longitudinal study comparing two groups of Japanese learners of English in two different learning environments, namely those of the target speech community, an ESL setting, and their home country, an English as a Foreign Language (EFL) context. The research focused on the degree of change that took place over time in the perception of social status in advice acts. The data were collected by means of a MCT, with 12 scenarios and four response choices for each scenario, which was administered four times throughout the academic year. Results from this study indicated that living and studying in an ESL setting had a positive impact on students' pragmatic development. Japanese ESL students' perceptions of social status in advice acts improved considerably more in comparison to EFL students since, over time, there was an increase in learners' understanding of how NSs perceived advice depending on social status. In view of her results, the author suggests that learners in an EFL context may require some pedagogical intervention to become pragmatically competent.

In another study with a latent longitudinal design, Matsumura (2003) examined learners' pragmatic development on the basis of their approximation to NSs' preferences for advice type depending on different social status. On the one hand, this study paid attention to the role played by learners' proficiency in the target language in their pragmatic development, that is, the cause-effect relationship between target language proficiency and pragmatic development. On the other hand, the author was also interested in analysing whether the amount of exposure, rather than the length of stay, was also an indicator of learners' pragmatic development. Results illustrated that the amount of exposure was potentially of great importance in learners' pragmatic development, in contrast to the level of proficiency. This finding supports previous research (Bardovi-Harlig 1999) that has demonstrated that students' having a high level of proficiency in the target language does not necessarily correlate with a high level of pragmatic improvement.

From the foregoing review of the literature, several assumptions may be mentioned. First, research focusing on suggestions is rather scarce, since there are very few studies dealing with this particular speech act, unlike others such as requests. Second, none of the studies examined to date take foreign language contexts into account with the exception of Koike's $(1994,1996)$ studies of Spanish as a foreign language. Third, none of the abovementioned studies have presented a taxonomy that includes different linguistic forms that may be employed when making suggestions in a variety of situations. For this reason, the elaboration of a taxonomy that can be used for the analysis of suggestions in the foreign language classroom is the focus of the next section. 


\subsection{Towards a taxonomy of suggestions}

The taxonomy presented in this study is based on two theoretical frameworks: speech act theory and politeness theory. On the one hand, speech act theory is particularly relevant, since we address those universal pragmatic strategies of direct and indirect types mentioned by Kasper and Schmidt (1996). On the other hand, these strategies are also related to the terms of on record and off record proposed in the politeness theory developed by Brown and Levinson $(1978,1987)$. Apart from these two theories, we have also considered Bardovi-Harlig and Hartford's (1996) maxim of congruence, which involves the appropriateness of specific strategies according to the speakers' status relative to one another in a given situation. Finally, we have relied on the previous research in the crosscultural and ILP fields examined above in order to adopt several linguistic realisations employed in those studies. Table 1 shows our proposed taxonomy of suggestion linguistic realisation strategies, which is divided into three main types: direct, conventionalised and indirect forms.

The first type of suggestion involves that of direct strategies, in which the speaker clearly states what he/she means. Direct suggestions are performed by means of performative verbs, a noun of suggestion or "illocutionary force indicating device" (Bardovi-Harlig and Hartford 1996: 180), imperatives and negative imperatives. Regarding the use of performative verbs, such as "I suggest that you change the date of the exam", several authors (Wardhaugh 1985; Koike 1994; Tsui 1994; Koester 2002) have argued that this formula is not widely employed in everyday life since it is regarded as very direct, although the data from NSs' oral and written production in different tasks that elicited suggestions (see Martínez-Flor [2004] for a detailed description of these tasks) show that it is sometimes employed for formal situations. Tsui (1994: 125) also considers the use of the noun to be a very direct suggestion, as in the example "My suggestion to you is to get into that". The use of imperatives are also regarded as the most direct and impolite forms of making a suggestion (Edmonson and House 1981; Koike 1994; Hinkel 1997) since they have the most literal pragmatic force, as in "Try using this computer" or "Don' $t$ try to use this program".

The type of conventionalised forms used to make suggestions (Banerjee and Carrell 1988) still allow the hearers to understand the speaker's intentions behind the suggestion, since the illocutionary force indicator appears in the utterance, although this second type of suggestion realisations is not as direct as the first type. Within this group, we find a greater variety of linguistic realisations to be employed, such as the use of specific formulae, expressions of possibility or probability, suggestions performed by means of the verbs should and need, and the use of the conditional. According to most of the authors (Wardhaugh 1985; Wierzbicka 1987; Koike 1994), the interrogative forms employed by using specific formulae such as "Why don't you phone this person?" or "What about making this choice?" are typical of suggestions. The other types of conventionalised forms follow the structure of declarative utterances (Koike 1994). Thus, expressions of possibility or probability which imply the use of modal verbs (Banerjee and Carrell 1988; Alcón and 
Safont 2001) have been considered as expressing suggestions (e.g. "You might want to leave this for tomorrow"). Other verbs such as should (Edmonson and House 1981; Banerjee and Carrell 1988; Koike 1994) or need (Bardovi-Harlig and Hartford 1996) are also employed when making conventionalised suggestions. The last strategy, that is to say using the conditional, has been defined by Koike (1996: 264) as "an irrealis clause in declarative form", and also serves to express a suggestion as in "If I were you, I would buy a new computer".

\begin{tabular}{|c|c|c|}
\hline TYPE & STRATEGY & EXAMPLE \\
\hline \multirow[t]{4}{*}{ DIRECT } & Performative verb & $\begin{array}{l}\text { I suggest that you ... } \\
\text { I advise you to ... } \\
\text { I recommend that you ... }\end{array}$ \\
\hline & Noun of suggestion & My suggestion would be ... \\
\hline & Imperative & Try using ... \\
\hline & Negative imperative & Don't try to ... \\
\hline \multirow[t]{5}{*}{$\begin{array}{c}\text { CONVENTIONALISED } \\
\text { FORMS }\end{array}$} & $\begin{array}{l}\text { Specific formulae } \\
\text { (interrogative forms) }\end{array}$ & $\begin{array}{l}\text { Why don't you ...? } \\
\text { How about ...? } \\
\text { What about ...? } \\
\text { Have you thought about ...? }\end{array}$ \\
\hline & Possibility/probability & $\begin{array}{l}\text { You can } \ldots \\
\text { You could ... } \\
\text { You may ... } \\
\text { You might ... }\end{array}$ \\
\hline & Should & You should ... \\
\hline & Need & You need to $\ldots$ \\
\hline & Conditional & If I were you, I would ... \\
\hline \multirow[t]{2}{*}{ INDIRECT } & Impersonal & $\begin{array}{l}\text { One thing (that you can do) would be } \\
\text {... } \\
\text { Here's one possibility: ... } \\
\text { There are a number of options that } \\
\text { you ... } \\
\text { It would be helpful if you ... } \\
\text { It might be better to ... } \\
\text { A good idea would be ... } \\
\text { It would be nice if ... }\end{array}$ \\
\hline & Hints & I've heard that ... \\
\hline
\end{tabular}

Table 1. Taxonomy of suggestion linguistic realisation strategies. ${ }^{2}$

The third group of strategies, that is, indirect suggestions, refers to those expressions in which the speaker's true intentions are not clearly stated. These indirect forms for suggestions do not show any conventionalised form, that is, there is no indicator of the suggestive force in the utterance, so the hearer has to infer that the speaker is actually making a suggestion. The use of different impersonal forms has been regarded as a way of making indirect suggestions (Hinkel 1994; Koike 1994), such as "It would be helpful if you 
could find his telephone number". In fact, taking into consideration Bardovi-Harlig and Hartford's (1996: 181) maxim of congruence, "the impersonal statements [...] can be used by students in exactly the same form as used by the advisor". Finally, the use of hints is the most indirect type of comment that can be employed in order to make a suggestion. An example of a hint would be "I've heard that the course is really difficult" (Hinkel 1997: 14), which should be inferred by the hearer as a suggestion not to take the course for his/her own benefit.

\section{A proposal for the use of suggestions in FLT}

After having presented our suggested taxonomy, the focus of this section aims to describe an example of a teaching approach in which such a taxonomy could be implemented in order to foster learners' pragmatic competence when making suggestions in the EFL classroom. Particularly, our proposal has been designed for learners engaged in a University degree of Computer Science, and it consists of five different stages based on Kasper's (1997) suggested activity types for developing pragmatics: i) awareness-raising activities, and ii) opportunities for communicative practice.

\subsection{Stage 1}

As a first step, learners should be presented with authentic input in which the speech act of suggesting is employed in real and natural settings. To that end, it has been demonstrated that most textbooks and other written manuals do not tend to be a good source of pragmatic input, since they show an artificial and decontextualised presentation of the different pragmatic aspects examined as well as a lack of natural conversational models representing the real use of language (Bardovi-Harlig et al., 1991; Boxer and Pickering, 1995; Mandala, 1999; Alcón and Safont, 2001). For this reason, it has been claimed that the use of video, films and TV can be a suitable material that presents authentic audiovisual input. In fact, in a series of studies conducted by Rose $(1993,1994,1997,2001)$, the author has pointed out that "in foreign language contexts, exposure to film is generally the closest that language learners will ever get to witnessing or participating in native speaker interaction" (Rose, 1997: 283). Thus, using excerpts from a film or contextualised videotaped situations could be a suitable starting point for a lesson in pragmatics. An example of this type of material is illustrated in Appendix $A$, which includes the script of a videotaped conversation between two students who are looking for information on the Internet in a computer lab. Such type of dialogue shows the two variables of power and social distance (Brown and Levinson, 1987), since the status between the two participants is equal and there is not a high social distance between them, as they are friends who already know each other. Therefore, the first step would involve making FL learners watch such a videotaped situation and then engage them in a series of activities that are explained in the following stage. 


\subsection{Stage 2}

Once learners have watched the videotaped situation, a series of awareness-raising activities that focus on the sociopragmatic aspects implied in such a conversation would be introduced. The purpose of these activities would be to make learners aware of the important role that social and contextual factors play in real-life situations. Thus, learners' awareness could be raised through questions such as What is happening? Where are the participants? What is their relationship? or What is the topic of the conversation? Next we provide some examples of this sort of activities which are based on the conversation presented in Appendix A:

\section{Example (1)}

You have seen a conversation between two people. Decide which the correct answer for each question is:

1. Where do you think the participants are?

$\square$ In a professor's office

$\square$ At home

$\square$ In a restaurant

- In a computer lab

2. What is the relationship between the participants?

$\square$ Stranger-stranger

$\square$ Doctor-patient

$\square$ Friend-friend

$\square$ Professor-student

3. What is the status between the participants?

$\square$ Tajala has a higher status than Christina

$\square$ Christina has a higher status than Tajala

$\square$ Both have an equal status

$\square$ One participant has a lower status

Apart from this activity based on the situation presented in the video, learners' attention could also be directed to the pragmalinguistic aspects involved when making suggestions. To this end, learners could be provided with the written video script of the videotaped situation (see Appendix $A$ ), and asked several questions that direct them to the different linguistic forms employed to make suggestions. Examples of these questions are:

Example (2)

Now read the transcript from the conversation you have just watched and decide which 
the correct answer for each question is:

1. What is Christina saying in lines 4-5?

$\square$ She wants to give Tajala some information.

$\square$ She thinks that Tajala is a good friend.

$\square$ She has a problem looking for some information.

$\square$ She thinks that Tajala needs some help.

2. What is Tajala doing in lines 10 and 12 ?

$\square$ She tells Christina about the new library.

$\square$ She asks Christina to help her.

$\square$ She suggests a place where Christina can find some information.

$\square$ She tells Christina about some new books.

3. What is Tajala doing in lines 36 and 37 ?

$\square$ She helps Christina looking for more information.

$\square$ She asks Christina to help her with Internet.

$\square$ She tells Christina that she knows a lot about Google.

$\square$ She wants Christina to find some information for her looking into Google.

\subsection{Stage 3}

At this stage, it would be very helpful to look for another situation (also related to the field of computer science) that involved two interlocutors with different sociopragmatic variables to those appearing in the previous situation, that is, with a different power relationship (i.e. higher status) and with a higher social distance between them (i.e. strangers who meet for the first time). Then, learners could be asked to watch the videotaped situation and do similar activities to those presented in the previous stage. After that, a series of questions in which learners have to compare both situations in terms of the social and contextual factors that characterise each one would be arranged. By means of this comparison-type of activity, learners' awareness could be raised towards the fact that sociopragmatic factors have an effect on the appropriate selection of a particular pragmalinguistic form when suggesting. An example of this sort of questions is as follows:

Example (3)

You have seen two different situations. In pairs, try to remember those situations and answer the following questions: 
1. Where do the situations take place?

2. What is the relationship between the participants in both situations?

3. What is the status between the participants in both situations?

\subsection{Stage 4}

Along with the previous awareness-raising activities, learners could be provided with metapragmatic explanations on the use of suggestions in case specific doubts might arise during the realisation of the activities. Then, they would be ready to receive explicit instruction on the appropriate use of suggestions by first explaining to them what the speech act of suggestion is. A possible definition that could be employed together with examples from the videotaped situation learners have watched is the following one:

A suggestion is an utterance that the speaker intends the hearer to perceive as a directive to do something that will be to the hearer's benefit. Therefore, the speaker is doing the hearer a favour, because it is not obvious to both the speaker and the hearer that the hearer will do the act without the suggestion being made. As you have just seen in the previous conversation, one of the participants has tried to help the other participant by suggesting that she did something.

Suggestions employed by Tajala (see Appendix A)

- "Have you tried the ERIC database?"

- "Why don't you go into the title?"

- "Another thing you might wanna try is Google"

She could have used other forms to make the suggestions. However, the appropriate choice of each linguistic form will depend on the contextual situation and the relationship between the participants.

Learners would, then, be presented with the taxonomy previously described in Section 2.3 (see Table 1). Here, learners would be explained the gradation of all the different linguistic formulae for suggesting on the basis of politeness criteria (Brown and Levinson, 1987). Thus, the direct pragmalinguistic forms would be regarded as less polite whereas the indirect formulae would be considered as the most polite forms. Additionally, special emphasis would be put on making learners understand the importance of employing different downgraders (i.e, perhaps, probably, maybe, just, I think, etc.) in order to soften 
the face-threatening nature of this speech act. Together with such an explicit explanation of the available range of linguistic formulae that learners can employ when making a suggestion, a multiple-choice activity could be prepared so that they can practise these forms in different contextual situations. An example of this sort of activity is presented below:

\section{Example (4)}

Taking into account the explanation on the use of different linguistic forms to make a suggestion, decide which suggestion would be more appropriate for the following situations:

Situation 1: Browsing the Web

You see one of your new classmates working in the library very late in the evening. This classmate is browsing the Web in order to find new information about Digital Electronics. Your new classmate looks very tired. What would you say to this classmate?

I would probably suggest that you go home and have a rest.

口 I'm not sure, but I think a good idea would be that you go home and have a rest.

$\square$ Perhaps you should go home and have a rest.

\section{Situation 2: Book about Internet2}

You and one of your professors meet in a computer bookshop. Your professor is considering buying an expensive book about Internet2 - a project about Internet applications for academic research, distance learning and education. However, you think that another computer shop may sell the book at a lower price. What would you say to your professor?

$\square$ Have you tried checking the price of this book in another computer shop?

$\square$ I think it might be better to check the price of this book in another computer shop.

$\square$ I think you need to check the price of this book in another computer shop.

\subsection{Stage 5}

Having become familiar with the variety of pragmalinguistic forms that can be employed for conveying the speech act of suggesting depending on the sociopragmatic factors involved in a particular situation, learners could be provided with a series of production activities in which they can implement all that knowledge (Kasper, 1997). First, several activities involving students' written production on suggestions could be introduced as semi-practice activities. The following is an example of this type of activity:

Example (5)

Read the following situations on your own and write what you would say in those situations:

$\underline{\text { Situation } 1}$

Your best friend would like to contact people from other countries in order to know other 
customs and be able to practise the English language. You think that using IRC (Internet relay $c h a t$ ) is a very good and fast way of meeting people from all over the world. What would you say to your friend?

\section{Situation 2}

One of your new professors tells the first day of the class that she is very keen on using Internet for all the activities in the class. She would like to have a more interesting, creative and interactive class. She asks students for ideas about different activities that could be done in this way. You have always wanted to take part in a newsgroup. So, what would you say to your professor?

Then, learners could work in pairs and write down a dialogue in which each learner assumes a different role. They would be asked to pay special attention to the social and contextual factors involved in each situation so that the suggestions to be made were appropriate accordingly. An example of this type of activity is as follows:

\section{Example (6)}

Read the following situations in pairs and imagine that each one of you have a different role (A \& B). Then, write what you would say in those situations:

\section{Situation 1}

A. You want to buy a new computer because yours is very old. You have heard that one of your new classmates bought one last week. You think that this classmate will have some information about different types of computers and prices, so you decide to ask this classmate.

B. You are new in the class. You bought a new computer last week and now you have a lot of information about different models and prices (see brochures). One of your classmates also wants to buy a new one. This classmate asks you for help. You suggest different options:-

PC vs. Macintosh-

Laptop vs. desktop-

Normal screen vs. flat screen-

Hardware and software 
Situation 2

A. Your English professor asks you to help her with a PowerPoint presentation. She has to present an important research article in a conference about new technologies next week. She knows that you are very fond of using PowerPoint and other programmes, so she asks you for suggestions. You suggest different options:

- Titles (type of letter, letter size, etc.)

- Use of different templates (different screens)

- Movement of these screens in the monitor

- Insert graphics, pictures, website links, etc.

B. You have to present a very important research article in a conference about new technologies next week. You ask one of your students to help you with a PowerPoint presentation.

Finally, learners would be provided with more opportunities for oral communicative practice. Among the activities designed to practice different pragmatic abilities, namely those of role-play, simulation and drama, role-play has been the activity that has been most frequently recommended for use (Rose, 1994; Trosborg, 1995; Kasper, 1997; Koester, 2002; among many others). Consequently, a series of role-plays could be used to develop learners' pragmatic performance when making suggestions. This type of activity would be ideal since it is one of the few possibilities that learners have to experiment and actively engage in a communicative situation in the foreign language classroom. Moreover, they would also be able to receive feedback from both the teacher and their peers regarding their performance in terms of pragmatic appropriateness. An example of different role-plays that could be designed is provided next:

Example (7)

Read the following role-plays and, after preparing them with your partner, perform them in front of the class.

\section{$\underline{\text { Role-play A }}$}

A. You meet one of your new classmates at the bus stop. You are talking about the new subject of Networks I. Your classmate tells you that she can't go to the class on Tuesdays and she would like to change to the practice group on Wednesday. Suggest that she talk to the professor to change the practice group.

B. You are with one of your new classmates at the bus stop. You are talking about the subject of Networks $I$. You tell this classmate that you can't go to the class on Tuesdays and that you would like to change to the practice group on Wednesday. Your classmate tells you to do something. 


\section{Role-play B}

A. You are talking to one of your professors after the class has finished. She just remembers that she has forgotten to tell the rest of the class that the next session will take place at the computer lab. Suggest that she post a sign outside the class.

B. You are talking to one of your students after the class. You tell him that you have forgotten to tell the rest of the class that the next session will take place at the computer lab. Your student tells you to do something.

\section{Conclusion}

In this paper, we have proposed a taxonomy for the analysis of the speech act of suggesting that has been drawn up on the basis of speech act and politeness theories as well as previous research conducted in both the cross-cultural and ILP fields. Taking into account the fact that the foreign language classroom has been regarded as an impoverished environment for the acquisition of pragmatic competence (Alcón, 2001), it is our belief that employing this taxonomy in such a context would be of benefit to foster learners' ability to make suggestions.

For this reason, a particular teaching approach has been proposed, showing how such a taxonomy could be presented to our learners and practiced through a series of awarenessraising activities and opportunities for communicative practice. By means of such an approach, learners could be made aware of the fact that, in order to make an appropriate use of the different linguistic formulae available for suggestions, several factors need to be considered, such as the situations where the suggestion is elicited, the contextual features involved in those situations, and the relationship between different participants that may appear in them.

The elaboration of our proposed taxonomy and its integration into particular FLT approaches, such as the one suggested in this paper, point to important pedagogical implications for the development of learners' pragmatic ability when making suggestions in different situations. Specifically, our suggested teaching approach has been designed for the Computer Science classroom, although both the awareness-raising and productive activities (i.e. role-plays) here presented could be adopted and tailor-made in other EFL contexts. This is, therefore, a task for the practising FL teacher who aims to integrate pragmatics into his/her current teaching syllabus.

\section{Notes}

1. This study is part of a research project funded by (a) a grant from the Spanish Ministerio de Educación y Ciencia (HUM2004-04435/FILO), co-funded by FEDER, and (b) a grant from Fundació Universitat Jaume I and Caixa Castelló-Bancaixa (P1.1B2004-34). The speech act 
examined in the present paper (i.e. suggestions) has been the focus of analysis in a larger study (Martínez-Flor, 2004).

2. The taxonomy is based on studies by Edmonson and House (1981), Wardhaugh (1985), Wierzbicka (1987), Banerjee and Carrell (1988), Beebe et al . (1990), Hinkel (1994, 1997), Koike (1994, 1996), Tsui (1994), Bardovi-Harlig and Hartford (1996), Kasper and Schmidt (1996), Schmidt et al. (1996), Alcón and Safont (2001) and Koester (2002).

\section{Works Cited}

Alcón, Eva (2001): "Developing pragmatic competence in the academic setting: The case of suggestions in NS/NNS advising sessions". In S. Posteguillo, I. Fortanet and J. C. Palmer, eds., Methodology and new technologies in language for specific purposes. Castelló: Servei de Publicacions de la Universitat Jaume I, 79-86.

Alcón, Eva and Pilar Safont (2001): "Occurrence of exhortative speech acts in ELT materials and natural speech data: A focus on request, suggestion and advice realisation strategies". SELL: Studies in English Language and Linguistics 3: 5-22.

Altman, Roann (1990): "Giving and taking advice without offense". In R. C. Scarcella, E. S.

Andersen and S. Krashen, eds., Developing communicative competence in a second language. Boston: Heinle and Heinle, 95-99.

Bach, Kent and R. M. Harnish (1979): Linguistic communication and speech acts. Cambridge, MA: MIT Press.

Banerjee, Janet and Patricia L. Carrell (1988): "Tuck in your shirt, you squid: Suggestions in ESL". Language Learning 38: 313-364.

Bardovi-Harlig, Kathleen and Beverly S. Hartford (1990): "Congruence in native and nonnative conversations: Status balance in the academic advising session". Language Learning 40: 467-501.

Bardovi-Harlig, Kathleen and Beverly S. Hartford (1993): "Learning the rules of academic talk: A longitudinal study of pragmatic development". Studies in Second Language Acquisition 15: 279-304. 171-188.

Bardovi-Harlig, Kathleen, Beverly S. Hartford, Rebecca Mahan-Taylor, Mary J. Morgan and Dudley W. Reynolds (1991): "Developing pragmatic awareness: Closing the conversation". ELT Journal 45: 4-15.

Beebe, Leslie M., Tomoko Takahashi and Robin Uliss-Weltz (1990): "Pragmatic transfer in ESL refusals". R. C. Scarcella, E. S. Andersen and S. Krashen, eds., Developing communicative competence in a second language. Boston: Heinle and Heinle, 55-73.

Boatman, Dana (1987): "A study of unsolicited advice". Penn Working Papers in Educational Linguistics 3(1): 35-60.

Boxer, Diana and Lucy Pickering (1995): "Problems in the presentation of speech acts in ELT materials: The case of complaints". ELT Journal 49: 44-58.

Brown, Penelope and Stephen C. Levinson (1987): Politeness: Some universals in language use. Cambridge: Cambridge University Press.

Edmonson, Willis and Juliane House (1981): Let's talk and talk about it. A pedagogic interactional 
grammar of English. München, Wien and Baltimore: Urban \& Schwarzenberg.

Haverkate, Henk (1984): Speech acts, speakers and hearers. Pragmatics and beyond 4. Amsterdam: John Benjamins.

Hinkel, Eli (1994): "Appropriateness of advice as L2 solidarity strategy". RELC Journal 25: 71-93.

. (1997): "Appropriateness of Advice: DCT and Multiple Choice Data". Applied Linguistics 18(1): 1-26.

House, Juliane and Gabriele Kasper (1981): "Politeness markers in English and German". In F. Coulmas, ed., Conversational routine. The Hague: Mouton de Gruyter, 157-185.

Hu, Wenzhong and Cornelius L. Grove (1991): Encountering the Chinese. Yarmouth, Maine: Intercultural Press.

Kasper, Gabriele (1997): "Can pragmatic competence be taught?" (Network, 6) [HTML document]. Honolulu: University of Hawaii, Second Language Teaching \& Curriculum Center. Available at http://www.nflrc.hawaii.edu/NetWorks/NW06/

Kasper, Gabriele and Richard Schmidt (1996): "Developmental issues in interlanguage pragmatics". Studies on Second Language Acquisition 18: 149-169.

Koester, Almut Josepha (2002): "The performance of speech acts in workplace conversations and the teaching of communicative functions". System 30: 167-184.

Koike, Dale April (1994): "Negation in Spanish and English suggestions and requests: Mitigating effects?" Journal of Pragmatics 21: 513-526.

. (1996): "Transfer of pragmatic competence and suggestions in Spanish foreign language learning". In S. M. Gass and J. Neu, eds., Speech acts across cultures. Berlin: Mouton de Gruyter, 257-281.

Li, Charles and Sandra Thompson (1981): Mandarin reference grammar. Berkeley, CA: University of California Press.

Lii-Shih, Yu-hewi E. (1994): Conversational politeness and foreign language teaching. Taipei, Taiwan: Crane Publishing.

Mandala, Susan (1999): "Exiting advice". In L. F. Bouton, ed., Pragmatics and language learning, vol. 9. Urbana, IL: University of Illinois at Urbana-Champaign, 89-111.

Martínez-Flor, Alicia (2004): The effect of instruction on the development of pragmatic competence in the English as a foreign language context: A study based on suggestions. Doctoral Dissertation. Castellón: Universitat Jaume I.

Matsumura, Shoichi (2001): "Learning the rules for offering advice: A quantitative approach to second language socialization". Language Learning 51: 635-679.

. (2003): "Modelling the relationships among interlanguage pragmatic development, L2 proficiency, and exposure to L2". Applied Linguistics 24(4): 465-491.

Rintell, Ellen (1979): "Getting your speech act together: The pragmatic ability of second language learners". Working Papers on Bilingualism 17: 97-106.

Rose, Kenneth R. (1993): "Sociolinguistic consciousness-raising through video". The Language Teacher 17: 7-9.

. (1994): "Pragmatic consciousness-raising in an EFL context". In L. F. Bouton and Y. Kachru, eds., Pragmatics and language learning, vol. 5. Urbana, IL: University of Illinois at Urbana-Champaign, 52-63.

. (1997): "Pragmatics in the classroom: Theoretical concerns and practical possibilities". In L. F. Bouton, ed., Pragmatics and language learning, vol. 8. Urbana, IL: University of 
Illinois at Urbana-Champaign, 267-295.

. (2001): "Compliments and compliment responses in film: Implications for pragmatics research and language teaching". International Review of Applied Linguistics 39: 309-326.

Schmidt, Richard and J. C. Richards (1980): "Speech acts and second language learning". Applied Linguistics 1: 129-157.

Schmidt, Richard, Akihiko Shimura, Zhigang Wang and Hy-sook Jeong (1996): "Suggestions to buy: Television commercials from the U.S., Japan, China, and Korea". In S. M. Gass and J. Neu, eds., Speech acts across cultures. Berlin: Mouton de Gruyter, 285-316.

Searle, John R. (1969): Speech acts: An essay in the philosophy of language. Cambridge: Cambridge University Press.

. (1976): "The classification of illocutionary acts". Language in Society 5: 1-24.

Thomas, Jenny (1995): Meaning in interaction. An introduction to pragmatics. New York: Longman.

Trosborg, Anna (1995): Interlanguage pragmatics. Requests, complaints and apologies. Berlin: Mouton de Gruyter.

Tsui, Amy (1994): English conversation. Oxford: Oxford University Press.

Wardhaugh, Ronald (1985): How conversation works. Cambridge, MA: Basil Blackwell.

Wierzbicka, Anna (1987): English speech act verbs. A semantic dictionary. Sydney, Orlando: Academic Press.

. (1991): Cross-cultural pragmatics: The semantics of human interaction. Berlin: Mouton de Gruyter. 
Appendix A. Script of a videotaped situation involving two students in a computer lab.

\begin{tabular}{|c|c|c|}
\hline 1. & Tajala: & Hi Christina \\
\hline 2. & Christina: & Hi Tajala. How are you doing? \\
\hline 3. & Tajala: & Good. What's up? What are you up to? \\
\hline $\begin{array}{l}4 . \\
5 .\end{array}$ & Christina: & $\begin{array}{l}\text { I can't find the ... I can't find any information on Multimedia } \\
\text { programmes. }\end{array}$ \\
\hline 6. & Tajala: & Multimedia? What do you need that for? \\
\hline 7. & Christina: & I'll just, ... this project that I'm doing. \\
\hline 8. & Tajala: & So, what site are you right now? \\
\hline 9. & Christina: & I'm in the University ... uh ... library. \\
\hline 10. & Tajala: & OK. Have you tried ... uh... the ERIC database? \\
\hline 11. & Christina: & Uh... I've never heard of it. \\
\hline $\begin{array}{l}12 . \\
13 .\end{array}$ & Tajala: & $\begin{array}{l}\text { Uh, um. OK, well, why don't you go into the title? It's a } \\
\text { pretty good database. It tells you ... where ... }\end{array}$ \\
\hline 14. & Christina: & [where to go?] \\
\hline 15. & Tajala: & The little index? Browse index by title \\
\hline 16. & Christina: & Uh, OK. \\
\hline 17. & Tajala: & Yeah \\
\hline 18. & Christina: & I should write this down. \\
\hline 19. & Tajala: & It's really helpful. \\
\hline 20. & Christina: & OK, let me get my pen. \\
\hline 21. & Tajala: & Have a piece of paper! \\
\hline 22. & Christina: & OK... Thank you. \\
\hline 23. & Tajala: & You're welcome. \\
\hline 24. & Christina: & $\mathrm{Mm} \ldots$.. OK, so you go into title ... \\
\hline 25. & Tajala: & and then, database, $\mathrm{OK} \ldots$ and then, just go down ... to \\
\hline 26. & & the middle ... and it's right there ... the educational \\
\hline 27. & & resources permission ... Yeah \\
\hline 28. & Christina: & ERIC, OK! \\
\hline $\begin{array}{l}29 . \\
30 .\end{array}$ & Tajala: & $\begin{array}{l}\text { and then just click on the ERIC ... [Christina clicking on that } \\
\text { site] yeah ... that! }\end{array}$ \\
\hline 31. & Tajala: & So, this is the database ... then you can just ... \\
\hline 32. & Christina: & Oh /guau/ \\
\hline $\begin{array}{l}33 . \\
34 .\end{array}$ & Tajala: & $\begin{array}{l}\text { you know, Multimedia, wherever type of word you're } \\
\text { looking for ... }\end{array}$ \\
\hline 35. & Christina: & Oh. That was very helpfull \\
\hline 36. & Tajala: & And then, another thing you might wanna try is Google? \\
\hline 37. & & Have you tried that? The search agent? \\
\hline 38. & Christina: & Oh. I never tried it. \\
\hline 39. & Tajala: & So $\ldots$ \\
\hline 40. & Christina: & Is this right here? \\
\hline $\begin{array}{l}41 . \\
42 .\end{array}$ & Tajala: & $\begin{array}{l}\text { Yeah. So, just type Google dot com and then you can } \\
\text { just type something really general ... Multimedia! }\end{array}$ \\
\hline 43. & Christina: & OK! [clicking] \\
\hline 44. & Tajala: & So, yeah, I guess you want different resources, may I give \\
\hline 45. & & you out some ... \\
\hline 46. & Christina: & Eh ... [writing down] Google \\
\hline 47. & Tajala: & dot com \\
\hline 48. & Christina: & dot com. OK! ... Oh. That's helpful. \\
\hline 49. & Tajala: & Yeah ... So, ... \\
\hline 50. & Christina: & Eh ... what time is it? \\
\hline $\begin{array}{l}51 . \\
52 .\end{array}$ & Tajala: & $\begin{array}{l}\text { Uh ... I think it's eight. Eight fifteen. Have you had } \\
\text { breakfast yet? }\end{array}$ \\
\hline 53. & Christina: & I haven't. \\
\hline 54. & Tajala: & Do you want some coffee or something? \\
\hline $\begin{array}{l}55 . \\
56 .\end{array}$ & Christina: & $\begin{array}{l}\text { That sounds great ... and I'll be back. Thank so much. That } \\
\text { was so helpful. }\end{array}$ \\
\hline 57. & Tajala: & No problem. Anytime. \\
\hline 58. & Christina: & OK. Let's go and get some coffee! \\
\hline
\end{tabular}

